Seminar Paper No. 709

BARGAINING STRUCTURE AND NOMINAL

WAGE FLEXIBILITY

by

Charlotta Groth and Åsa Johansson

INSTITUTE FOR INTERNATIONAL ECONOMIC STUDIES Stockholm University 
Seminar Paper No. 709

\title{
BARGAINING STRUCTURE AND NOMINAL WAGE FLEXIBILITY
}

\author{
by
}

Charlotta Groth and Åsa Johansson

Papers in the seminar series are published on the internet in Adobe Acrobat (PDF) format.

Download from http://www.iies.su.se/

Seminar Papers are preliminary material circulated to stimulate discussion and critical comment.

May 2002

Institute for International Economic Studies

S-106 91 Stockholm

Sweden 


\title{
Bargaining Structure and Nominal Wage Flexibility*
}

\author{
Charlotta Groth ${ }^{\dagger}$ and Åsa Johansson ${ }^{\ddagger}$
}

February 2002

\begin{abstract}
In a model with heterogenous agents, wage setting by monopoly unions and monetary policy conducted by a central bank, we show that the duration of nominal wage contracts is u-shaped in the degree of centralization, with intermediate bargaining systems yielding contracts of shorter duration and thus more flexible nominal wages than both decentralized and centralized systems. We also find the optimal level of centralization of wage bargaining to be negatively related to the degree of heterogeneity in the economy. The theoretical predictions of the model are tested on OECD data. There is empirical support for the main results regarding contract length, while there is less support for the predictions regarding the level of centralization.
\end{abstract}

JEL Classification: C21, E24, E32, J51

Key Words: nominal wage flexibility, contract length, bargaining structure, monetary policy

\footnotetext{
${ }^{*}$ We are grateful to Lars Calmfors, Lars E.O. Svensson, Anne Boschini, Steinar Holden, Peter Skogman and participants in seminars at the IIES, Stockholm University; the Department of Economics, Uppsala University; and the EEA meeting 2001 for helpful comments and advice. We also thank Christina Lönnblad for editorial assistance. Any remaining errors are the responsibility of the authors.

${ }^{\dagger}$ Institute for International Economic Studies, Stockholm University, 10691 Stockholm, Sweden. Email: charlotta.groth@iies.su.se.

${ }^{\ddagger}$ Institute for International Economic Studies, Stockholm University, 10691 Stockholm, Sweden. Email: asa.johansson@iies.su.se.
} 


\section{Introduction}

In the Neo-Keynesian literature, nominal rigidity in wages and prices is a crucial element in explaining employment and output fluctuations over the business cycle (for recent overviews, see e.g. Taylor, 1999; Woodford and Rotemberg, 1999). In this paper, we focus on wage rigidities, which, according to recent findings in Gali, Gertler and LopezSalido (2001a,b), contribute more to macroeconomic fluctuations than price rigidities.

There are a number of explanations for the existence of rigid nominal wages, such as downward rigidity due to social norms preventing nominal wage cuts (see e.g. Akerlof and Yellen, 1990), unsynchronized wage setting leading to rigid aggregate nominal wages (see e.g. Taylor, 1979; Calvo, 1983) and the existence of a contract cost, which gives rise to fixed nominal wages for a period of time (e.g. Gray, 1976, 1978; Ball, 1987).

The focus of this paper is on contract costs as an explanation of nominal wage rigidity. The idea in the literature is that negotiating wages is costly, so that it may be optimal to fix nominal wages for a period of time. However, this comes at a disadvantage, since the wage rate does not change in response to unexpected events, which causes costly fluctuations in employment and output. The earlier literature studies how the trade-off between reducing the per-period contract cost, on the one hand, and increasing output and employment fluctuations, on the other hand, is affected by the volatility of both real and nominal shocks. The contract cost is taken as exogenous in this literature.

In this paper, we argue that contract costs should not be treated as exogenous to the system within which wages are negotiated. In particular, the hypothesis put forward is that one important determinant of the size of contract costs is the degree of centralization/coordination of wage setting. ${ }^{1}$ The idea is that the degree of centralization affects contract length in two opposite ways; an increase in centralization reduces the number of negotiations that need to be undertaken in the economy, which tends to reduce the total contract cost, and thereby, reduce contract length. At the same time, coordination can be costly in itself when various employers and unions have to reach an agreement on a common stand in wage negotiations. This tends to increase the contract cost, which, in

\footnotetext{
${ }^{1}$ The degree of coordination of wage bargaining here refers to the extent to which bargaining is coordinated across industries, unions etc. Examples of coordination can be common expiration dates and wage norms that set the standard across the economy. Centralization here refers to the level at which wage bargaining takes place, ranging from decentralized bargaining at the company level, to intermediate bargaining at the industry level and centralized bargaining with negotiations between nationwide labor and employers' federations. See e.g Calmfors et al. (2001) for a discussion of the relationship between the two concepts of coordination and centralization.
} 
turn, increases the duration of contracts. The net impact on contract length depends on the relative strength of these effects, but in the general case, a u-shaped relation between the degree of centralization and the size of the contract cost should be expected.

The idea that contract costs depend on the degree of centralization has been discussed by Calmfors et al. (2001) and to some extent, by Murphy (2000), but a more systematic analysis yet remains to be done. ${ }^{2}$ The purpose of this paper is therefore to model the link between the degree of centralization and contract length, and to test the predictions of the model on data.

The model is based on a setup originally developed by Gray (1978). To model contract length, we assume that wage rigidities are produced by a contract cost that consists of both a fixed and a variable part, where the variable part represents the coordination cost that arises when various unions must reach a common stand. To motivate the coordination cost, we introduce heterogeneity into the model, which has not been done in the earlier literature. The motivation is that for a given degree of centralization, coordination costs should be higher in a more heterogenous society, thereby yielding longer wage contracts.

The introduction of heterogenous agents and a contract cost that depends on the degree of centralization leads naturally to the question of whether centralization can be treated as exogenous. So far, this has been the standard assumption in the literature on wage setting (for overviews, Flanagan, 1999; Calmfors et al., 2001), although the degree of centralization has been endogenized in some recent work. Holden (2001) models the choice of coordination as a game where unions decide to coordinate when the gain from doing so for each union outweigh the benefits from deviating from the coordinated solution. Holden studies how the trade-off is affected by the monetary regime and finds that the gains from coordination are larger with a more accommodating central bank. Lindbeck and Snower (2001) discuss the implications of the move from occupational specialization towards multi-tasking for the degree of centralization of wage setting. They show that under such re-organization, centralized wage setting becomes inefficient and argue that this could be a reason for the recent trend towards decentralization in many countries. Here, we follow this recent line of literature by endogenously modelling the degree of centralization. We assume that in each wage setting round, the degree of centralization is

\footnotetext{
${ }^{2}$ There are some empirical results on the relation between contract length and the size of the bargaining unit. Murphy (2000) regresses the duration of nominal wage contracts on a set of explanatory variables, including the number of employees covered by the contract. This variable enters positively but not significantly. Christofides and Wilton (1983) use two proxies for contract costs: A dummy variable distinguishing between contracts involving more or less than 1000 employees and a dummy variable indicating within which industry the contract was signed. They find no evidence that these variables matter for contract length.
} 
chosen by a union confederation. The confederation chooses the degree of centralization that maximizes the total utility of the work force belonging to the confederation. Wagesetting units are then formed and a common wage rate is implemented for all members of a particular wage-setting unit. ${ }^{3}$

One result is that for a sufficiently large fixed contract cost, contract length is $\mathrm{u}$ shaped in the degree of centralization, with intermediate wage setting systems being more flexible than both centralized and decentralized systems. Another result of our model is that the optimal level of centralization is decreasing in the degree of heterogeneity in the society. The theoretical predictions regarding contract length are supported by data, using a sample of 17 OECD countries for two time periods. There is less support for the predictions regarding the degree of centralization.

The structure of the paper is the following. Section 2 gives the basic model. Section 3 analyzes the choice of contract length for a given the degree of centralization. Section 4 models the choice of the degree of centralization. Section 5 performs comparative statics and section 6 takes the model to the data. Finally, section 7 concludes.

\section{The model}

\subsection{The sequence of the game}

In the first stage of the game, the degree of centralization is optimally chosen by the union confederation and local wage-setting units are formed. Thereafter, the wage-setting units determine a contract specifying a fixed nominal wage rate and contract length. The productivity level varies during the time of the contract and since the nominal wage is preset, it cannot be altered in response to productivity changes. The central bank is, however, able to change the price level and thereby stabilize employment.

The game is repeated and once wage contracts expire, the game starts all over again. There are no endogenous state variables that link the periods together, which means that in each period, the agents solve a static problem. ${ }^{4}$ The model is solved by backward induction, where the choice of centralization in the first stage acts as a constraint for the second stage choices of contract length and nominal wages.

\footnotetext{
${ }^{3}$ Naturally, this is a simplification of reality, where the wages implemented differ across firms and industries. However, our assumption is intended to capture the fact that wage dispersion tends to be lower in centralized wage bargaining systems compared to more decentralized ones (see e.g Rowthorn, 1992; or Wallerstein, 1999).

${ }^{4}$ This means that we focus on history-independent equilibria, which excludes any kind of historydependent trigger strategies, such as those analyzed by e.g Holden (2001).
} 


\subsection{Production}

The private sector consists of a continuum of perfectly competitive firms, defined on the interval $0<i \leq 1$. At each firm there is a fixed pool of workers attached. The production function of firm $i$ is given by

$$
y_{i t}=a l_{i t}+\theta_{t}+q_{i}
$$

where $y_{i t}$ is the log of output of firm $i$ at time $t, l_{i t}$ is the log of labor input of firm $i$ at time $t, \theta_{t}$ is a productivity shock common to all firms at time $t$ and $q_{i}$ is an idiosyncratic component indexing the firm-specific productivity level. This idiosyncratic component is constant over time and uniformly distributed on the support $[-\rho / 2, \rho / 2]$ with density function $\varphi(q)=1 / \rho$. The shock $\theta_{t}$ is a Brownian motion, which is a continuous-time counterpart of a random walk, with zero mean and instantaneous variance $\sigma_{\theta}^{2}$. This means that the conditional forecast variance of $\theta_{T}$ at time $t$, with $T>t$, is given by $(T-t) \sigma_{\theta}^{2}$, where the increasing variance over time captures the idea that there is greater uncertainty about more distant points in the future. The labor share $a$ fulfills $0<a \leq 1$.

For firm $i$, profit maximization gives labor demand as

$$
l_{i t}^{d}=\mu\left(p_{t}-w_{i t}+\theta_{t}+q_{i}+\ln a\right),
$$

where $\mu=1 /(1-a)$ is the labor demand elasticity, $p_{t}$ is the log of the price level and $w_{i t}$ is the log of the nominal wage. The labor supply of workers in firm $i^{\prime} s$ pool is

$$
l_{i t}^{s}=\delta\left(w_{i t}-p_{t}\right)
$$

where $\delta \geq 0 .{ }^{5}$ We can now define the efficient level of employment at firm $i$ in period $t$ as the employment level at which $l_{i t}^{d}=l_{i t}^{s}$. This is denoted by $l_{i t}^{*}$ and equals

$$
l_{i t}^{*}=\frac{\delta \mu}{\delta+\mu}\left(\theta_{t}+q_{i}+\ln a\right) .
$$

In the short run, employment is demand determined. The idea behind this is that unions determine a nominal wage fixed for a period of time and during the time of the contract, each worker commits to providing the firm with the demanded labor. Thus, during the time of the contract, workers may be off their labor supply schedule. ${ }^{6}$

\footnotetext{
${ }^{5}$ This type of labor-supply schedule is commonly used in the literature and can be derived from microfoundations in a setting where the household's utility depends positively on consumption and negatively on the supply of labor.

${ }^{6}$ This is a common assumption in the literature on contract costs and indexation where the nominal wage is fixed for a period of time.
} 


\subsection{The price level}

The central bank conducts monetary policy with the aim to stabilize fluctuations in the price level and in aggregate employment. The instantaneous loss of the central bank is given by

$$
L_{t}^{c b}=p_{t}^{2}+\lambda\left(l_{t}-l_{t}^{*}\right)^{2}
$$

where $l_{t}=\int_{i} l_{i t} d i$ is the aggregate employment at time $t, l_{t}^{*}=\int_{i} l_{i t}^{*} d i$ is the aggregate efficient level of employment in the economy at time $t$, and $\lambda$ is the weight on deviations in employment relative to deviations in the price level from their respective target levels. ${ }^{7}$ The central bank is assumed to have instantaneous control over the price level. At each instant $t \geq 0$, after having observed the realization of the productivity shock $\theta_{t}$, the central bank sets the price level so as to solve

$$
\min _{p_{t}} L_{t}^{c b}
$$

subject to $(2),(4),(5)$, and the definitions of $l_{t}$ and $l_{t}^{*}$. The optimal price level is given by

$$
p_{t}=b\left(w_{t}-\frac{\mu}{\mu+\delta}\left(\ln a+\theta_{t}\right)\right),
$$

where $b=\lambda \mu^{2} /\left(1+\lambda \mu^{2}\right)$ and $w_{t}=\int_{i} w_{i t} d i$ is the aggregate nominal wage at time $t$, which is taken as given by the central bank. In response to a productivity shock, the price level is moved in the opposite direction to stabilize employment. Moreover, the coefficient $b$ is smaller that one, which means that the central bank only stabilizes productivity shocks partially, and the reason for this is that fluctuations in the price level are costly. The amount of stabilization $b$ is increasing in the weight on employment fluctuations relative to price level fluctuations, $\lambda^{8}$

\subsection{The labor market}

\subsubsection{Unions}

Labor is organized in one union confederation and at each firm there is a local union branch. This means that there is a continuum of union branches defined on the interval

\footnotetext{
${ }^{7}$ With this specification of the loss function, the central bank cares about fluctuations in aggregate employment around the aggregate efficient level. This yields the same decision rule as in the case when the central bank cares about the integral over the deviations of employment from the efficient level of each individual firm.

${ }^{8}$ There are no demand shocks in the model. However, including demand shocks do not matter for the results, since the central bank will fully stabilize demand shocks and thus leave the price level and contract length unaffected.
} 
$0<i \leq 1$, and below, we shall order them according to their firm-specific productivity level, $q_{i}$. The union confederation can choose to set wages on different levels, for instance at firm-, industry- or nation-wide level, and the level at which wages are set will determine the degree of centralization of wage setting in the economy. When choosing the level at which wages are set, the union confederation minimizes a loss function that covers all local union branches belonging to the confederation and once the wage-setting units have been formed, a common wage rate is determined in each wage-setting unit.

To simplify the analysis, wage setting is assumed to be symmetrical, with all wagesetting units of equal size. Further, the idiosyncratic component is observable and in the coordination process, the wage-setting units are formed in such a way that the variance of $q_{i}$ is minimized within each unit. This means that the local unions coordinate with those which are closest to themselves on the unit interval, and this minimizes the efficiency loss that arises from setting a common wage for each wage-setting unit.

We can now define $c$ as the share of the union confederation that is organized in a wage-setting unit. When $c$ tends to zero, wage setting is fully decentralized, with wages determined at each firm. When wage setting is fully centralized, wages are determined economy-wide, and the wage-setting unit consists of the whole economy with $c$ equal to one. ${ }^{9}$

Finally, the wage-setting units are denoted by $I_{j}$ with $j=1,2, \ldots, 1 / c$, and with $1 / c$ being the number of wage-setting units in the economy. ${ }^{10}$

The above is illustrated in Figure 1, where the idiosyncratic productivity level $q_{i}$ is plotted against the union index. The firm-specific productivity level $q_{i}$ is symmetric around zero, strictly increasing in $i$, with $c$ being the share of the economy organized in the wage-setting unit $I_{j}$.

\footnotetext{
${ }^{9}$ This is of course a simplification. In reality, not all union branches belong to the same union confederation.

${ }^{10}$ For analytical simplicity, $1 / c$ is treated as a continuous variable. In practice, it will be an integer.
} 


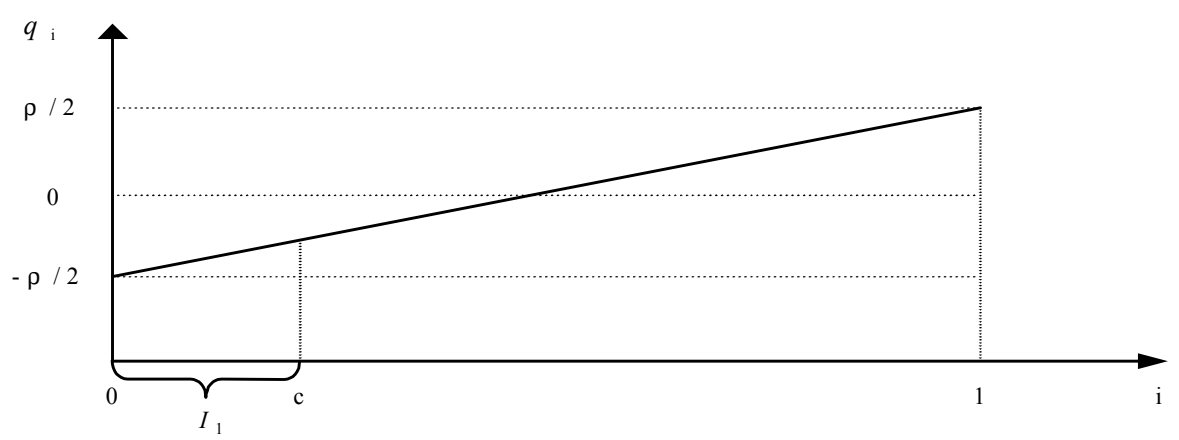

Figure 1: The labor market

\subsubsection{Contract costs}

Determining wages is costly and the contract cost $K$ of each wage-setting unit is determined by

$$
K=F+H(c, \rho),
$$

where $F$ is a fixed contract cost and $H(c, \rho)$ is a variable cost, which depends both on the size of the wage-setting unit, $c$, and the degree of heterogeneity, $\rho$. The fixed cost is independent of the level at which wage setting takes place and motivated by the fact any negotiation can be seen to involve a certain degree of effort (resources). The variable part represents the idea that coordination in itself might involve costs. The specification of the coordination cost is discussed and motivated in Appendix A.1, where it is shown that under certain reasonable assumptions, it fulfills

$$
H(c, \rho)=c^{\alpha} \rho^{\beta},
$$

where $\alpha>1$ and $\beta>0$, which implies that $H_{c}>0, H_{\rho}>0$ and $H_{c c}>0$. The specification implies that the coordination cost is convex in the degree of centralization, increasing in the degree of heterogeneity, and equal across all wage-setting units (which have been assumed to be of the same size).

\section{Choice of contract length and the nominal wage}

In the second stage of the game, the degree of centralization is given from the first stage and taken as exogenous by the wage-setting units when new contracts are signed. There is synchronized wage setting and all contracts are signed at time $t=0$. The contract of wage-setting unit $I_{j}$ specifies the value of two parameters: The nominal wage $w_{j 0}$ and 
contract length $x_{j 0} \cdot{ }^{11}$ Once contracts expire, new ones are renegotiated. In a symmetric equilibrium, all wage-setting units will choose the same contract length $x_{j 0}=x$. This means that there is synchronized wage setting in any period, $t \geq 0$. To simplify the notation we shall therefore suppress the time subscript on contract length.

An optimal choice of the nominal wage and contract length minimizes the expected loss per unit of time for the local unions belonging to wage-setting unit $I_{j}$. The expected loss during a contract period is determined by the sum of (1) the deviations of employment from the target level, which is equal to the efficient level of employment and (2) the contract cost, which is incurred at the time when the contract is being negotiated. ${ }^{12}$ This means that $w_{j 0}$ and $x_{j}$ minimize the loss function $L_{j}$

$$
L_{j}=\frac{1}{x_{j}}\left[\int_{i \in I_{j}}\left\{\int_{0}^{x_{j}} \mathrm{E}_{0}\left[\left(l_{i t}-l_{i t}^{*}\right)^{2}\right] d t\right\} d i+K\right],
$$

where sub-index $j$ refers to the wage-setting unit, while sub-index $i$ refers to the local union belonging to wage-setting unit $I_{j}$. The inner integral is the expected loss from deviations of employment from target during the time of the contract for the local union branch. ${ }^{13}$ The total loss is then the integral of the expected loss over all local unions belonging to unit $I_{j}$, that is, for all $i \in I_{j}$.

\subsection{The choice of an optimal wage}

The optimal wage rate $w_{j}$ for wage-setting unit $I_{j}$ solves

$$
\frac{\partial L_{j 0}}{\partial w_{j 0}}=\frac{\partial}{\partial w_{j 0}}\left[\frac{1}{x_{j}}\left(\int_{i \in I_{j}}\left\{\int_{0}^{x_{j}} \mathrm{E}_{0}\left[\left(l_{i t}-l_{i t}^{*}\right)^{2}\right] d t\right\} d i+K\right)\right]=0 .
$$

\footnotetext{
${ }^{11}$ The first subscript refers to the wage-setting unit while the second refers to the time at which the nominal wage and contract length are chosen.

${ }^{12}$ To justify the loss function in more detail, one can assume that workers are risk-neutral so that their utility is equal to the consumer surplus. Contract signers are then assumed to maximize the sum of expected profits and the expected consumer surplus (the joint surplus). This is equivalent to minimizing the expected reduction in the joint surplus from deviations of employment from the efficient employment level plus the contract cost. As shown in Appendix B.1, $\left(l_{i t}-l_{i t}^{*}\right)^{2}$ is a second-order Taylor approximation of the losses from deviations of employment form the efficient level.

${ }^{13}$ Here, we assume that there is no breach of contract. This corresponds to the inclusion of a peace clause which is common practice in most countries, as reported in SOU (1998).
} 
By using (2) together with (4) and (7) to get an expression for the squared deviation of employment from the target, the first-order condition can be expressed as

$$
\int_{i \in I_{j}}\left\{\int_{0}^{x_{j}} \frac{\partial}{\partial w_{j 0}} \mathrm{E}_{0}\left\{\left[\mu\left(b w_{t}-w_{j 0}\right)+k(1-b)\left(\ln a+\theta_{t}\right)+k q_{i}\right]^{2}\right\} d t\right\} d i=0
$$

where $z=\mu^{2} /(\mu+\delta) \cdot{ }^{14}$ By evaluating the derivative, this can be expressed as

$$
\int_{i \in I_{j}}\left\{\int_{0}^{x_{j}}\left[\mu\left(b \mathrm{E}_{0}\left[w_{t}\right]-w_{j 0}\right)+k(1-b)\left(\ln a+\theta_{0}\right)+k q_{i}\right] f_{j t} d t\right\} d i=0
$$

where we have used that $\mathrm{E}_{0}\left[\theta_{t}\right]=\theta_{0}$ and where the inner derivative is denoted by $f_{j t}$, equal to

$$
f_{j t}=\mu\left(b \frac{\partial \mathrm{E}_{0}\left[w_{t}\right]}{\partial w_{j 0}}-1\right)
$$

The first term in the parenthesis is the marginal effect on the price level in period $t$ of a change in the individual wage $w_{j 0}$. This effect works through the effect on the aggregate wage expected to prevail in period $t$. The second term is the marginal effect on the individual wage $w_{j 0}$. Thus, the inner derivative can be interpreted as the marginal change in the individual real wage $w_{j 0}-p_{t}$ expected to prevail in period $t$.

In the analysis below, we restrict ourselves to considering a symmetric Nash Equilibrium, in which all wage-setting units choose the same contract length $x_{j}=x$. The wage-setting units choose the same contract length since they all face the same trade-off between reducing contract costs, on the one hand, and increasing the intertemporal loss from fluctuations in employment around target, on the other hand. This means that at any time $0 \leq t \leq x$, the aggregate wage $w_{t}$ is equal to the aggregate wage implemented at time $t=0$, denoted by $w_{0}$ and equal to

$$
w_{0}=c \sum_{j=1}^{1 / c} w_{j 0}
$$

By using this in (13), the inner derivative simplifies to

$$
f_{j t}=\mu(b c-1) .
$$

Since $f_{j t}$ is a constant and equal across all wage-setting units, it does not affect the firstorder condition (12). When evaluating (12), we then use the feature that all terms can be

\footnotetext{
${ }^{14}$ Since $x_{j}$ and $w_{j 0}$ are chosen simulanously, $x_{j}$ is independent of $w_{j 0}$. This means that the derivative can be evaluated within the integrals.
} 
treated as constants when evaluating the integral with respect to $t$. Moreover, all terms except $q_{i}$ can be treated as constant when evaluating the integral with respect to $i$. The first-order condition can then be expressed as

$$
c \mu\left(b w_{0}-w_{j 0}\right)+c k(1-b)\left(\ln a+\theta_{0}\right)+k \int_{i \in I_{j}} q_{i} d i=0 .
$$

Solving for $w_{j 0}$ gives

$$
w_{j 0}=b w_{0}+\frac{1}{\mu}\left[k(1-b)\left(\ln a+\theta_{0}\right)+k \bar{q}_{j}\right],
$$

where $\bar{q}_{j}=1 / c \int_{i \in I_{j}} q_{i} d i$ is the average value of the firm-specific productivity level in wage-setting unit $I_{j}$, discussed in Appendix A.1. Thus, the optimal wage $w_{j 0}$ depends on $\theta_{0}$ since this is the expected value of the common productivity level during the time of the contract, and on the average firm-specific productivity level in unit $I_{j}$, since this determines the expected loss from setting a common wage for the representative member of the wage-setting unit. Moreover, it depends on the aggregate wage rate during the time of the contract, $w_{0}$, since this affects monetary policy.

By using (14), we can solve for the aggregate wage $w_{0}$, equal to

$$
w_{0}=c \sum_{j=1}^{1 / c}\left\{\frac{1}{\mu}\left[b w_{0} k(1-b)+\left(\ln a+\theta_{0}\right)+k \bar{q}_{j}\right]\right\} .
$$

By summing over the wage-setting units, we get the following expression for the aggregate wage:

$$
w_{0}=\frac{k}{\mu}\left(\ln a+\theta_{0}\right),
$$

where we have used that the expected value of $q_{i}$ in the whole economy is equal to zero. By using this in (15), the individual wage for wage-setting unit $j$ can be expressed as

$$
w_{j 0}=\frac{k}{\mu}\left(\ln a+\theta_{0}\right)+\frac{k}{\mu} \bar{q}_{j}
$$

where the nominal wage depends on the common productivity level during the time of the contract and on the average firm-specific productivity level in wage-setting unit $I_{j}$.

\subsection{The optimal contract length}

The next step is to use the expression for an optimal wage to solve for optimal contract length. By inserting (7), (16) and (17) into (2) and using the definition of $l_{i t}^{*}$, the total 
integral over the squared deviation of employment from the target for wage-setting unit $I_{j}$ can be expressed as

$$
\int_{i \in I_{j}} \mathrm{E}_{0}\left[\left(l_{i t}-l_{i t}^{*}\right)^{2}\right] d i=c k^{2}(1-b)^{2} t \sigma_{\theta}^{2}+\frac{k^{2} \rho^{2} c^{3}}{12}
$$

where we have used that $\mathrm{E}_{0}\left[\theta_{t}^{2}\right]=t \sigma_{\theta}^{2}$. The first term is the intertemporal loss that arises from increasing contract length and which results from the fact that the degree of uncertainty regarding the level of productivity is increasing over time. Thus, longer contract periods come at the cost of larger employment fluctuations because the nominal wage cannot be adjusted to unforeseen events during the contract period. The second term is the atemporal efficiency loss that comes from the fact that a wage-setting unit sets a single wage only. The atemporal loss is given by the term $\int_{i \in I_{j}}\left(q_{i}-\bar{q}_{j}\right)^{2} d i$ which, as can be seen in Appendix A.1, is equal across all wage-setting units and equal to $c^{3} \rho^{2} / 12$. To solve for optimal contract length, expression (18) is inserted into the expected loss (9). By evaluating the derivative with respect to $x$, we get the following first-order condition for an optimal contract length,

$$
-\frac{1}{x^{2}}\left[\int_{0}^{x}\left(c k^{2}(1-b)^{2} t \sigma_{\theta}^{2}+\frac{k^{2} \rho^{2} c^{3}}{12}\right) d t+K\right]+\frac{1}{x}\left(c k^{2}(1-b)^{2} x \sigma_{\theta}^{2}+\frac{k^{2} \rho^{2} c^{3}}{12}\right)=0
$$

which is equal across all wage-setting units. The first term corresponds to the per unit of time savings on costs achieved by lengthening the contract. The second term is the increased loss in the form of larger employment fluctuations resulting from lengthening the contract period. At the margin, the gains from lengthening the contract should equal the expected loss.

After evaluating the integral and simplifying where we use (8) to substitute for $K$, the optimal contract length can be represented by:

$$
x=\sqrt{\frac{2(F+H(c, \rho))}{c k^{2}(1-b)^{2} \sigma_{\theta}^{2}}} .
$$

Here, we see that contract length depends on the trade-off between contract costs (the numerator in (20)) and the increased intertemporal loss in terms of larger deviations of employment from target, due to the preset nominal wage (the denominator in (20)). Contract length does not, however, depend on the atemporal efficiency losses from implementing a common wage rate in a wage-setting unit. The reason is that contract length trades off variability over time against the contract cost for a given efficiency loss. 
The relation between $x$ and $c$ is important for the analysis and discussed in the following proposition:

Proposition 1 For a sufficiently large fixed contract cost F, contract length is u-shaped in the level of centralization.

A proof of this proposition is included in Appendix B.2. The intuition behind the result is that an increase in $c$ has two effects on contract length. One the one hand it reduces the fixed contract cost per union member, which makes it optimal to write shorter contracts. One the other hand, an increase in $c$ raises the coordination cost, which tends to give longer contracts. At lower levels of centralization, the first effect dominates as long as the fixed contract cost is sufficiently high. At higher levels of centralization, the second effect is stronger.

The following proposition relates contract length to the exogenous variables of the model:

Proposition 2 An increase in $\lambda$ increases the contract length. A higher $\rho$ causes the contract length to rise. An increase in $\sigma_{\theta}^{2}$ decreases the contract length and finally, an increase in the fixed cost $F$ causes the contract length to increase.

The derivative of $x$ with respect to $\lambda$ depends positively on $\mathrm{k}(1-b) \partial b / \partial \lambda$ where $k(1-b)>0$. A higher value of $\lambda$ implies that the central bank stabilizes employment to a larger extent, which means that $\partial b / \partial \lambda>0$, and thus the cost of prefixing wages decreases. Hence, contract length increases. An increase in $\rho$ implies that the coordination cost, and thus the total contract cost rises, which strengthens the incentives to write longer contracts. An increase in the fixed cost $F$, also raises the total contract cost and thus also causes $x$ to rise. Finally, an increase in the variability of real shocks gives shorter contracts, since prefixing wages becomes more costly in terms of larger employment fluctuations. ${ }^{15}$

\footnotetext{
${ }^{15}$ This result is well established in the literature where it is shown that higher volatility, both in real and nominal variables, causes shorter contract length (Gray, 1976, 1978; Calmfors and Johansson, 2001). In a somewhat different set-up by Danziger (1988), where firms are risk neutral and wage-earners are risk adverse, there is a distinction between real and nominal shocks. It is shown that optimal contract length is increasing in the variability of real shocks and decreasing in the variability of nominal shocks. The intuition is that labor contracts are designed to allocate risk efficiently in order to reduce the impact of uncertainty on risk-averse workers. During a contract period a firm may insure the workers, partially or fully, against real shocks. However, when the contract expires, a new contract is negotiated and this contract reflects worker productivity at the time of negotiation. This means that in the new contract workers are exposed to the real shocks that occured within the previous contract period.
} 


\section{Choice of the degree of centralization}

So far, the degree of centralization $c$ has been treated as given. In the first stage of the game, centralization is optimally determined by the union confederation by minimizing the aggregate loss for the work-force belonging to the union confederation. Thus, the relevant loss function is

$$
L=\sum_{j=0}^{1 / c} L_{j}
$$

where $1 / c$ is the number of wage-setting units in the economy and $L_{j}$ is the expected loss for wage-setting unit $I_{j}$ evaluated under the optimal choice of $x_{j}$ and $w_{j 0}$. (9) together with (18) gives the following expression for the expected loss for wage-setting unit $I_{j}$,

$$
L_{j}=\frac{1}{x}\left[\int_{0}^{x}\left(c k^{2}(1-b)^{2} t \sigma_{\theta}^{2}+\frac{k^{2} \rho^{2} c^{3}}{12}\right) d t+K\right],
$$

where $x$ is given by (20). Since the expected loss is equal for all wage-setting units, (21) can be simplified to

$$
L=\frac{1}{c} L_{j}
$$

An optimal choice of $c$ then satisfies

$$
\frac{\partial L}{\partial c}=-\frac{1}{c^{2}} L_{j}+\frac{1}{c} \frac{\partial L_{j}}{\partial c}=0 .
$$

By evaluating this derivative, using (22) and (8) the first-order condition can be expressed as

$$
\frac{c k^{2} \rho^{2} x}{6}+\frac{H_{c}}{c}-\frac{K}{c^{2}}=0
$$

where we have used that $\partial L_{j} / \partial x=0$ at the optimal choice of $x .^{16}$

A marginal increase in the degree of centralization has three effects on the expected loss. The first term in (23) represents the fact that in larger wage-setting units, the degree of heterogeneity in terms of the firm-specific productivity parameter $\rho$ is larger. Since all members must agree on a common wage, this causes larger atemporal efficiency losses in terms of a larger squared deviation of employment from the target. The second term captures the fact that as centralization increases, the variable contract cost rises, which causes a further increase in the expected loss. The third term finally captures the fact that an increase in the degree of centralization decreases the contract cost per member of the wage-setting unit, which decreases the expected loss.

\footnotetext{
${ }^{16}$ In appendix C.1, it is shown that there exists a unique solution to (23) satisfying the conditions for a minimum.
} 


\section{Comparative statics}

The purpose of this section is to evaluate how the optimal level of centralization is affected by the parameters of the model. For proofs of the propositions, we refer to appendix D.1. Proposition 3 An increase in the degree of heterogeneity, $\rho$, causes the degree of centralization of wage setting to fall.

This is an intuitive result. There are two effects at work. First, for a given level of centralization, an increase in $\rho$ causes larger deviations of employment from the target, since more heterogenous labor has to agree on a common wage. Second, an increase in $\rho$ also increases the coordination cost, and makes it more costly for the local union branches to come to an agreement on a common wage. Both effects tend to reduce the optimal degree of centralization.

Proposition 4 An increase in $\lambda$ causes the degree of centralization of wage setting to fall.

An increase in $\lambda$ causes the central bank to stabilize employment to a larger extent. This reduces the disadvantage following from employment variability of writing long contracts, which leads to longer contracts. Hence the contract cost per unit of time is reduced. This, in turn, causes $c$ to fall, since it is less beneficial to share the contract cost, when it is smaller.

Proposition 5 An increase in the volatility of real shocks causes the degree of centralization of wage setting to increase.

The intuition behind this result is that an increase in the variability of real shocks increases the cost of writing long contracts. Hence contracts become shorter and the contract cost per unit of time increases. This makes it more advantageous to share the cost between several local union branches, which implies that the optimal degree of centralization increases.

Proposition 6 An increase in the fixed contract cost has an ambiguous effect on the optimal degree of centralization of wage setting.

The effect of $F$ is ambiguous since the direct and the indirect effects on $c$ go in opposite directions. An increase in $F$ tends to make it more favorable to coordinate wage setting at a higher level to divide the fixed cost among more local union branches. Thus, the direct effect tends to increase the degree of centralization. But an increase in $F$ also causes contract length to increase, which means that the contract cost per unit of time falls. This reduces the optimal degree of centralization. The outcome depends on which of the two effects that dominates. 


\section{Empirical results}

The purpose of this section is to evaluate empirically the results regarding both contract length and the degree of centralization of wage bargaining. The analysis is based on data for 17 OECD countries for two time periods, 1975-1985 and 1986-1995. ${ }^{17}$

\subsection{The data}

There is a lack of cross-country data on contract length. We therefore use data by Bruno and Sachs (1985) on the duration of nominal wages for 1975-85 and update the dataset for 1985-95. Countries are classified according to the average duration of nominal wage contracts, both across the economy and across time. The data is then grouped into an index, which can take three values: The value is 0 for the duration of nominal wage contracts less or equal to one year, the value is 1 for the duration of nominal wage contracts of one to three years and the value is 2 for duration of nominal wage contracts equal to or longer than three years. In what follows, this variable is denoted $x$.

As a measure of the degree of centralization, we use EMS by Elmeskov, Martin and Scarpetta (1998). This is a pure measure of the degree of centralization of wage bargaining, which classifies countries into groups depending on whether wage bargaining is decentralized $(\mathrm{EMS}=1)$, intermediate $(\mathrm{EMS}=2)$ or centralized $(\mathrm{EMS}=3)$. In the robustness checks, we consider two alternative indices: ESUM by Elmeskov, Martin and Scarpetta (1998), which is a summary measure where the index on centralization is combined with an index on the degree of coordination of employers and unions, and OECD by OECD (1997), which is a pure measure of centralization. ${ }^{18}$

One way of measuring the relative weight of employment stability in the central bank's preference function is to focus on the formal independence of the central bank. The idea is that independent central banks are more conservative than political authorities in the sense that they attribute more importance to the goal of price stability (for a discussion, see e.g. Cukierman, 1992). One drawback of using such a measure is that it does not take other means of achieving price stability into account. To account for this, we use a composite measure of central bank independence, CBI, by Iversen (1998), which combines a measure of central bank independence with a measure of the relative strength of the

\footnotetext{
${ }^{17} \mathrm{~A}$ summary of the industrial relations in the countries is included in Appendix E, and Table 1 provides an overview of the data.

${ }^{18} \mathrm{OECD}$ is available for three points in time: 1980,1990 and 1994 . We use the observations from 1980 for the first period and those from 1990 for the second period. EMS and ESUM are available from the 1980 's, with indications when changes in the systems have occurred.
} 
currency. The measure of formal central bank independence is based on the three most commonly used measures of central bank independence (Bade and Parkin, 1982; Grilli, Masciandro and Tabellini, 1991; and Cukierman et al., 1992), and the hard currency measure is based on average relative growth in nominal effective exchange rates. The combined continuous measure is normalized between 0 and 1 and is increasing in the degree of conservativeness of the central bank, which means that CBI is decreasing in the parameter $\lambda$ in our model. ${ }^{19}$

As a proxy for $\rho$, which is the width of the distribution of the idiosyncratic productivity component, the variable HET is used. In the model, capital is normalized to one. This means that a straight-forward way of measuring labor productivity would be to calculate value added per number of employed. In reality however, the size of the capital stock varies, both over time and across industries. To control for the size of the capital stock, we therefore calculate the productivity measure as the value added per number of employed times the labor share of value added. ${ }^{20}$ HET is then constructed as the variance of the productivity measure across industries in a given country, where the weight of a particular industry is given by the percentage contribution of the industry in GDP. The data are OECD data on value added in constant prices to the number of employed, the labor share of value added and the share of GDP for industries classified by the ISIC code rev2 (OECD, 2000).

VAR is the variance of real shocks which, in the model, corresponds to unexpected changes in labor productivity. This is a difficult factor to measure, but changes in labor productivity should affect the level of real output. To calculate unexpected changes in real output, we calculate the variance of real GDP relative to a trend, where trend output has been estimated using a Hodrick-Prescott filter, using quarterly IFS data on real GDP (IMF, 2000). To control for possible endogeneity problems, the measure VAR is based on historical data; that is, for the first period (1975-1985), data from 1970 to 1980 is used and for the second period, data from 1970 to 1990 is used. ${ }^{21}$ It is likely that VAR

\footnotetext{
${ }^{19}$ The original index is available for 15 OECD countries, and is updated for the remaining countries in the data set (Australia and Spain). The index is available on a yearly basis for the time period 1973 to 1995 and averages have been created for the sub-periods 1973-1985 and 1986-1995.

${ }^{20}$ Assuming a Cobb-Douglas production function of the form $F(L, K)=L^{\alpha} K^{1-\alpha}$, the derivative $\partial F(L, K) / \partial L=\alpha F(L, K) / L$, which corresponds to our measure which is the labor share $\alpha$ times the value added per number of employed $F(L, K) / L$.

${ }^{21}$ If data on individual wage agreements were available, the measure VAR should be calculated using historical data up to the quarter before the wage contract was signed. Here, however, we only have average data on contract length over a period of time. We therefore calculate VAR using data up until the middle of the period.

Moreover, to calculate trend GDP, we use as much historical data as possible. Therefore, the starting
} 
captures demand shocks as well as productivity shocks. However, by looking at relative output variability among countries it seems that different types of supply shocks have been the dominant source of fluctuations in the economy (see e.g. Clarida and Gali, 1994; Canzoneri et al., 1996; Thomas, 1997). The measure VAR can therefore be regarded as a reasonable approximation of the variance of productivity shocks.

The model also predicts that fixed contract costs should affect the outcome. Under the assumption that the fixed contract cost mainly depends upon the legal system within the country, a legal dummy could be used. Here we follow La Porta et al. (1999) and divide the countries into four subgroups: Common law, German civil law, French civil law and Scandinavian law (COM, GER, FRE, SCA). ${ }^{22}$ Another approach would be to look at the fixed contract cost as mainly culturally determined. However, the correlation between the legal indices and cultural/geographical indices (Scandinavia, Anglosaxian countries, Continental Europe, Mediterranean Europe, and Japan) is high, and the results are unaffected to the specification of the fixed cost. We will therefore only report results using the legal dummies.

Another factor that may affect the results is the size of the population. In the model, the population size is normalized to one, while in reality, it differs across countries. We therefore control for the size of the population, and the population variable is denoted POP (OECD, 2001). There could also be more general time trends, such as trends towards more decentralized wage bargaining and trends in population growth. To control for this, we also include a time dummy, which is denoted TIME.

\subsection{Data comments}

The first comment regards the sample size. The sample consists of 17 countries across two periods of time, and data is missing for some of the variables, (see Table 1 in the appendix). This means that the sample is small, and that the results have to be interpreted with caution. In the study, the result will only be regarded as indicative.

Table 1 shows the data for the more important variables contract length (denoted by $x_{1}$ for period $1, x_{2}$ for period 2 ), the degree of centralization $\left(\mathrm{EMS}_{1}\right.$ for period 1 , $\mathrm{EMS}_{2}$ for period 2), the degree of central bank independence $\left(\mathrm{CBI}_{1}\right.$ for period $1, \mathrm{CBI}_{2}$ for

\footnotetext{
point for calculating trend GDP is 1970 for both periods.

${ }^{22}$ In different regions, different types of law systems have developed. German, French and Scandinavian law are all examples of civil law. This has developed as an instrument of the state in expanding its power. It is largely based on created legislature and is focused on discovering a just solution to a dispute rather than following a just procedure that protects individuals against the state. Common law, which is mainly found in Anglosaxian countries, puts more emphasis on private rights of individuals.
} 
period 2), the variability of productivity across industries, $\left(\mathrm{HET}_{1}\right.$ for period $1, \mathrm{HET}_{2}$ for period 2) and the variance of real shocks $\left(\mathrm{VAR}_{1}\right.$ for period $1, \mathrm{VAR}_{2}$ for period 2). The variable contract length has 12 observations for short contracts $(x=0), 16$ observations for intermediate contract length $(x=1)$ and 6 observations for long contracts $(x=$ 2). Further, there are 9 observations for decentralized wage bargaining (EMS $=1$ ), 17 observations for intermediate wage bargaining $(\mathrm{EMS}=2)$ and 6 observations for centralized wage bargaining (EMS $=3$ ). Thus, there are relatively few observations for long contracts and centralized wage bargaining and this means that we have to be careful in analyzing potential outliers driving the results.

\subsection{The regression specification}

The first-order conditions of the model they imply propositions 3 to 6 that relate the optimal level of centralization to the exogenous variables of the model. This gives the following empirical specification

$$
c=\alpha_{0}+\alpha_{1} Y+\varepsilon_{1},
$$

where $c$ is a measure of centralization, $Y$ is a vector of exogenous variables, and $\varepsilon_{1}$ is the error term of the regressions.

Further, propositions 1 and 2 relate contract length to the level of centralization and to the exogenous variables of the model. This gives the following specification of the regression equation:

$$
x=\beta_{0}+\beta_{1} c+\beta_{2} c^{2}+\beta_{3} Y+\varepsilon_{2},
$$

where $x$ is the duration of nominal wages. To allow for a u-shaped relation between $x$ and $c, c^{2}$ is included in the regression. ${ }^{23}$

The empirical specification of the structural model is a recursive system and under the assumption that the error terms are not correlated, the single equation OLS generally gives unbiased and consistent estimates of the structural parameters of the model.

However, we do not have data on neither contract length nor the degree of centralization of wage bargaining. Instead, we have an index which maps the latent variable to an observed ordinal measure which takes the form of an ordered index. Using OLS in such case results in biased estimates and non-normal residuals. As an alternative, the model can be estimated using maximum likelihood for the ordered probit model (for an overview,

\footnotetext{
${ }^{23}$ Due to the small sample, it is not possible to test the specific functional forms of the model. Rather, the purpose is to test whether the implied derivatives of the model have the correct signs.
} 
see e.g. Greene, 1997; Long, 1997). However, the properties of consistency, normality and efficiency for ordered probit models have been proven to hold in large samples. In smaller samples, the behavior of the maximum likelihood estimator for these models is not well known. Thus, there could be potential problems using ordered probit for a sample as small as ours. We therefore choose to estimate the model using both estimation methods.

\subsection{Regression results using OLS}

In a first set of regressions, propositions 1 and 2 are tested by estimating equation (25). The results are reported in Table II. For a sufficiently large fixed cost of contracting, the model predicts a u-shaped relation between $x$ and $c$, which corresponds to a negative sign on $c$ and a positive sign on $c^{2} \cdot{ }^{24}$ As is clear from Table I, this is supported by data. Moreover, in the sample, there are countries where an increase in the degree of centralization decreases contract length, and countries where an increase in the degree of centralization increases contract length. ${ }^{25}$ The variables CBI and VAR both enter positively, which is opposite to the theoretical predictions. HET does not enter significantly. The fit of the regression is relatively high, explaining around 36 percentage points of the variation in contract length. As a robustness check, we reestimate the model using the centralization indices ESUM and OECD. The results are mainly robust to the choice of index. There is somewhat less support for a u-shaped relation using the OECD index. Potential outliers have been analyzed, and the results are not driven by outliers.

In a second set of regressions, propositions 3 to 6 , which relate the optimal degree of centralization to the exogenous variables of the model, are tested by running the regression specified in (24). The results are reported in Table III in the Appendix. Using the centralization index EMS, there is no support in favor for the main hypothesis that an increase in the degree of heterogeneity decreases the degree of centralization. The legal dummies explain a large share of the variation in EMS, indicating that in many countries, the wage setting system seems to be determined by historical and regional factors and that it cannot be chosen freely by the participants in the labor market, at least not in the short run. Moreover, the population size enters negatively, indicating that it may be easier to centralize wage bargaining in smaller countries. The results are somewhat

\footnotetext{
${ }^{24}$ The derivative of $x$ with respect to $c$ in regression (25) is equal to $\beta_{1}+2 \beta_{2} c$ and the second derivative is $2 \beta_{2}$. For $x$ to be u-shaped in $c$, we need the second derivative to be positive and the first derivative to be negative for smaller values and positive for larger values of $c$. This corresponds to having $\beta_{2}$ positive and $\beta_{1}$ negative.

${ }^{25}$ The derivative $d x / d(\mathrm{EMS})=-2.47+1.22 *(\mathrm{EMS})$. For a degree of centralization larger than two $($ EMS $>2)$ the derivative is positive.
} 
modified using the ESUM and the OECD indices in that they support a negative relation between HET and the degree of centralization. A possible explanation for the difference is the construction of the centralization indices. The ESUM index incorporates the degree of coordination of wage bargaining into a pure index of centralization. Countries with an intermediate degree of centralization, scores high in the ESUM but not in the EMS index. Moreover, the majority of these countries are relatively homogenous. ${ }^{26}$ The OECD index also assigns a higher degree of centralization to a larger number of countries, and this gives rise to a negative relation between the degree of heterogeneity and the degree of centralization. The remaining results are robust to the choice of centralization index.

\subsection{Regression results using ordered probit}

The linear specification in (24) and (25) relates a continuous dependent variable to the explanatory variables of the model. We do not have data on the underlying latent variables, since the data is expressed as an index, which only takes on certain values. Using ordered probit, the purpose is rather to estimate the implied cut off values, which translate the underlying latent variable into an index. The probit model assumes that the latent variable is a normally distributed random variable, so that the probability of observing a particular value of the index can be calculated from the cumulative distribution function.

The model is estimated using a maximum likelihood method, in which the objective is to find the parameter estimators which maximize the likelihood that the index would take on its particular values given the assumptions about the distribution of the latent variable.

In a first set of regressions, we estimate the relation between contract length $x$ and the set of explanatory variables. One of the explanatory variables, the degree of centralization, takes the form of an index and, two dummy variables, $c 1$ and $c 3$ are therefore created; $c 1$ takes the value of one when EMS is equal to one, otherwise, it is zero, $c 3$ is equal to one when EMS is equal to 3. Otherwise, it is zero.

The results are reported in Table IV. Included in the table are the explanatory variables that enter significantly. Using an ordered probit model, one has to be careful in interpreting the coefficients in the estimated regressions. The coefficients do not represent the marginal effects as in the OLS model. Instead, the ordered probit model estimates the predicted probabilities of observing a given outcome, conditional on the set of explana-

\footnotetext{
${ }^{26}$ For instance, Austria, Germany and Spain, (period 1) and, Austria, Germany, Netherlands and Denmark (period 2) are classified as centralized using ESUM, while they are intermediate in the EMS index. Out of these countries, four has a level of HET varying between 1.28 and 2.30.
} 
tory variables. The interpretation of the results will therefore be based upon predicted probabilities.

To proceed, we calculate the probabilities of observing short, intermediate and longterm wage contracts, given that the degree of centralization is low, intermediate and high. ${ }^{27}$ The results are reported in Table V. On the horizontal axis, the duration of wage contracts is indicated (short, intermediate and long-term contracts). On the vertical axis, the degree of centralization is represented (low, intermediate and high degree of centralization). It is clear that in intermediate bargaining systems, the probability of observing short wage contracts is higher than in decentralized and centralized systems. In decentralized and centralized bargaining systems, there is instead a higher probability of observing intermediate to long-term wage contracts. This supports the predictions of the model of a u-shaped relation between contract length and the degree of centralization.

The variable CBI enters significantly and an increase in the degree of central bank independence increases the probability of observing short contracts as shown in Table VI, where on the horizontal axis, the duration of wage contracts is indicated (short, intermediate and long-term contracts), and on the vertical axis, the degree of central bank independence is represented (low and high degree of independence). This is in line with the predictions of the model. The measure of productivity, VAR, enters significantly but only marginally affects the predicted probabilities of observing contracts of different lengths. Thus, contract length tend to be unaffected by the variance of productivity across time.

As a measure of fit, we use pseudo- $R^{2}$, which predicts that the model improves the explanatory power with around 35 percentage points compared to a model which only has a constant as independent variable. ${ }^{28}$ Finally, in a robustness check, we also find that these results are robust to the choice of centralization index.

Next, we estimate the relation between the degree of centralization and the set of explanatory variables. None of the variables in the model enter significantly (see Table VII), while the legal dummies and the size of the population enter significantly. There

\footnotetext{
${ }^{27}$ To calculate the predicted probability of observing a particular outcome, for a given value of one of the explanatory variables (here, the degree of centralization), it is common to fix all other explanatory variables at their means, and then let the variable of interest vary. Here, this method is difficult to use, since many dummy variables enter as explanatory variables. Therefore, the predicted probabilities are calculated as the means for the respective group, (here for countries with low, intermediate and high degree of centralization, respectively) given the actual values of all other explanatory variables.

${ }^{28}$ Let $L_{1}$ be the $\log$ likelihood of the full model and let $L_{0}$ be the log likelihood of a model with a constant only as independent variable. The pseudo- $R_{2}$ is defined as $1-L_{1} / L_{0}$, with 1 corresponding to perfect fit (with $L_{1}$ equal to zero), and 0 corresponding to no improvement in fit compared to a model with a constant only $\left(L_{1}=L_{0}\right)$.
} 
is also a significant time effect, suggesting that there is a lower probability of observing a high degree of centralization during the latter period. The pseudo- $R^{2}$ is 45 percentage points.

In the robustness check, when using the ESUM index, the degree of heterogeneity HET enters significantly, with a higher degree of heterogeneity reducing the probability of observing a high degree of centralization. ${ }^{29}$

To sum up, the empirical findings are relatively robust to the choice of estimation method. The results support a u-shaped relation between contract length and the degree of centralization. However, there is less support for a negative relation between the degree of heterogeneity and the degree of centralization. The results regarding the other variables (VAR and CBI) are less robust and in particular, depend on the estimation method.

\section{Conclusion}

The hypothesis in this paper is that the degree of centralization of wage setting is important in determining contract length, and that the centralization level itself is a function of the degree of heterogeneity in the economy.

Contract length is modelled as a function of contract costs, where the cost consists of one fixed and one variable part that depends on the degree of centralization. It is shown that under reasonable assumptions, the variable part is convex in the degree of centralization and increasing in the degree of heterogeneity. For a sufficiently large fixed contracting cost, this yields a u-shaped relation between contract length and the degree of centralization. Thus, intermediate wage setting systems tend to be more flexible than both centralized and decentralized systems.

The optimal degree of centralization is endogenized and modelled as a function of the degree of heterogeneity. The model predicts a negative relation between these variables. First, an increase in the degree of heterogeneity creates larger employment fluctuations, since more heterogenous labor has to agree on a common wage. Second, an increase in the degree of heterogeneity increases the coordination cost, and makes it more costly for the local union branches to make an agreement on a common wage. This tends to reduce the optimal degree of centralization.

The predictions of the model are tested on a cross-sectional sample of 17 OECD countries, covering two periods of time. Due to the lack of cross-country data on the variables

\footnotetext{
${ }^{29}$ In the robustness check, only ESUM is used. The reason for this is that OECD has a finer division of the degree of centralization (with 6 subgroups). It can therefore be considered as approximatively continuous and it is not used in the ordered probit regressions.
} 
included in the regressions, the results should be interpreted as mainly being indicative. The empirical results, both using OLS and ordered probit estimation methods, support a u-shaped relation between contract length and the degree of centralization, with intermediate wage setting systems being more flexible than both decentralized and centralized systems. There is less evidence of the negative relation between the centralization level and the degree of heterogeneity, something we interpret as a result of the fact that in many countries, the wage setting system is to a large extent historically and culturally determined, and cannot be chosen freely by the participants in the labor market, at least not in the short run. This has not been incorporated in the model, where we consider the unconstrained choice of centralization.

To sum up, we take a first step towards endogenizing the contract cost, although the wage setting process is still trivial. As an extension, the game between unions and employers, on the one hand, and the game between unions within the same wage-setting units, on the other hand, could be modelled to further deepening the understanding of wage setting and its implications on contract length and the degree of centralization. Moreover, the driving force behind centralization in our model is the incentive to reduce the fixed contract cost per wage-setting unit. The model does not capture other reasons for centralization, such as competition and internalization effects, discussed in e.g. Calmfors et al., (2001) and Flanagan, (1999). 


\section{References}

Akerlof, G.A., and Yellen, J.L., (1990), "The Fair Wage-Effort Hypothesis and Unemployment", Quarterly Journal of Economics, vol. 105.

Bade, R. and Parkin, M., (1982), "Central Bank Laws and inflation - A Comparative Analysis", Mimeo, University of Western Ontario.

Ball, L., (1987), "Externalities from Contract Length", American Economic Review, vol. 77 .

Bruno, M. and Sachs, J.D., (1985), "Economics of Worldwide Stagflation", Blackwell Publishers, Oxford.

Calmfors, L., Booth A., Burda, M., Checchi, D., Naylor, R., and Visser, J., (2001), "The Future of Collective Bargaining in Europe", in Boeri, T., Brugiavini, A. and Calmfors, L., (Eds), The Role of Unions in the Twenty-First Centrury, Oxford University press, Oxford.

Calmfors, L. and Johansson, Å., (2001), "Nominal Wage Flexibility, Wage Indexation and Monetary Union", mimeo, Stockholm University.

Calvo, G., (1983), "Staggered Prices in a Utility Maximizing Framework", Journal of Monetary Economics, vol. 12.

Canzoneri, M., Valles, J., and Vinals, J., (1996), "Do Exchange Rates Move to Address International Macroeconomic Imbalances?", CEPR Discussion Paper No. 1498.

CEOE, (1999), "Results of CEOE Survey on Collective Bargaining 1999 - Structure and Content of Collective Bargaining Agreements in Spain", Labor Relations Department.

Chapple, S., (1996), "Money Wage Rigidity in New Zeeland", Labor Market Bulletin, no. 2 .

Christofides, L.N. and Wilton, D.A., (1983), "The Determinants of Contract Length: An Empirical Analysis Based on Canadian Micro Data", Journal of Monetary Economics, vol. 12 .

Clarida, R. and Gali, J., (1994), "Sources of Real Exchange Rate Fluctuations: How Important are Nominal Shocks?", CEPR Discussion Paper No. 951.

Confederation of German Employers, (2000), Written materials, unpublished.

Confederation of Norwegian Business and Industry, (2000), Written materials, unpublished.

Confederation of Netherlands Industry and Employers, (2000), Written materials, unpublished.

Cukierman, A., (1992), Central Bank Strategy, Credibility, and Independence: Theory and Evidence, MIT press, Cambridge and London. 
Cukierman, A., Webb, S. and Neyapti, B., (1992), "Measuring the Independence of Central Banks and its Effect on Policy Outcomes", World Bank Economic Review, vol. 6.

Danziger, L., (1988), "Real Shocks, Efficient Risk Sharing, and the duration of Labor Contracts", Quarterly Journal of Economics, vol. 103.

Elmeskov, J., Martin, J.P. and Scarpetta, S., (1998), "Key Lessons for Labour Market Reforms: Evidence from OECD Countries Experiences", Swedish Economic Policy Review, vol. 5 .

Ferner, A. and Hyman, R., (1998) "Changing Industrial Relations in Europe", Blackwell Publishers, Oxford.

Flanagan, R. J., (1999), "Macroeconomic Performance and Collective Bargaining: An International Perspective", Journal of Economic Literature, vol 37.

Gali, J., Gertler, M. and Lopez-Salido, J.D., (2001a), "European Inflation Dynamics", European Economic Review, vol. 45.

Gali, J., Gertler, M. and Lopez-Salido, J.D., (2001b), "Markups, Gaps and Economic Fluctuations", Mimeo, Universitat Pompeu Fabra.

Gray, J.A., (1976), "Wage Indexation: A Macroeconomic Approach", Journal of Monetary Economics, vol. 2.

Gray, J.A., (1978), "On Indexation and the Contract Length, Journal of Political Economy", vol. 86.

Greene, W. H., (1997), Econometric Analysis, 3rd edition, Prentice-Hall, Inc., New Jersey.

Grilli, V., Masciandro, D. and Tabellini, G., (1991), "Political and Monetary Institutions and Public Finance in the Industrial Countries", Economic Policy, vol. 6.

Holden, S., (2001), "Monetary Regimes and the Co-ordination of Wage Setting", CESifo Working Papers 429.

Hunt, I. and Provis, C., (1995), "The New Industrial Relations in Australia", The Federation Press, Leichhart.

IMF, (2000), International Financial Statistics, Database.

Inoue, S., (1999), "Japanese trade unions and their future: Opportunities and challenges in an era of globalization", Rengo Institute for Advancement of Living Standards, Tokyo.

Iversen, T., (1998), "Wage Bargaining, Central Bank Independence and the Real Effects of Money", International Organization, vol. 52. 
Lindbeck, A. and Snower, D.J., (2001), "Centralized Bargaining and Reorganized Work: Are they Compatible?", European Economic Review, vol. 45.

Long, S.J., (1997), Regression models for categorical and limited dependent variables, Thousand Oaks, California.

Murphy, J. K., (2000), "What Effects does Uncertainty have on Contract Length?", Labour Economics, vol. 7.

New Zeeland Council of Trade Unions, (2000), Written material, unpublished.

OECD, (1998), Economic Surveys, New Zealand, OECD.

OECD, (1997), Employment Outlook, OECD.

OECD, (2000), OSC - OECD Statistical Compendium, Main Industrial Indicators, OECD.

OECD, (2001), Labour Force Statistics.

OEGB, (1999), Written material, unpublished.

La Porta, R., Lopez-de-Silanes, F., Shleifer, A., and Vishny, R., (1999), "The Quality of Government", Journal of Law, Economics and Organization, vol. 15.

Rowthorn, R. E., (1992), "Centralisation, Employment and Wage Dispersion", Economic Journal, vol. 102.

Statens offentliga utredning, 1998:141, "Ekonomisk utveckling, arbetsrätt och förhandlings-

system i några länder", in Medling och lönebildning.

Taylor, J., (1979), "Staggered Wage Setting in a Macro Model", American Economic Review, vol. 69 .

Taylor, J., (1999), "Staggered Price and Wage Setting in Macroeconomics", in Taylor, J.B., Woodford, M. (Eds.), Handbook of Macroeconomics, Vol 1.

Thomas, A., (1997), "Is the Exchange Rate a Shock Absorber? The Case of Sweden", IMF Working Paper 97/176.

Wallerstein, M., (1999), "Wage-Setting Institutions and Pay Inequality in Advanced Industrial Societies", American Journal of Political Science, vol. 43.

Woodford, M., and Rotemberg, J.J., (1999), "The Cyclical Behaviour of Prices and Costs", in Taylor, J.B., Woodford, M. (Eds.), Handbook of Macroeconomics, vol 1. 


\section{A The model}

\section{A.1 The Coordination cost}

An underlying assumption of the model is that the members of a wage-setting unit must agree on a common wage. When agreement is costly, so that it takes time and resources to reach a common agreement, it is plausible to assume that the coordination cost is proportional both to the size of the wage setting group and the degree of heterogeneity within the group. One measure representing the degree of heterogeneity is the variance of the firm-specific productivity level, which satisfies

$$
\int_{i \in I_{j}}\left(q_{i}-\bar{q}_{j}\right)^{2} \frac{1}{c} d i
$$

where $\bar{q}_{j} \equiv 1 / c \int_{i \in I_{j}} q_{i} d i$ is the average value of the firm-specific productivity level in wage-setting unit $I_{j}$ and where $1 / c$ is the density function of firms in group $I_{j}$. To solve for this, rewrite $\bar{q}_{j}$ as

$$
\bar{q}_{j}=\frac{1}{c} \int_{\phi_{j}}^{\phi_{j}+c} q_{i} d i=\frac{1}{c} \int_{\phi_{j}}^{\phi_{j}+c}(-\rho / 2+\rho i) d i
$$

for an arbitrary limit of integration $\phi_{j}$ and where the function $-\rho / 2+\rho i$ maps $\rho$ into $i$. That is, for each $i$ between 0 and 1 , there is an associated productivity level $q_{i}$ that fulfills $-\rho / 2+\rho i$, where $-\rho / 2$ is the productivity level for $i=0$ and where $\rho i$ is the increment in the productivity level for member $i \in(0,1)$. By solving for the above integral, we get

$$
\bar{q}_{j}=-\rho / 2+\phi_{j} \rho+\rho c / 2 .
$$

This states that the average productivity level in group $I_{j}$ is equal to $-\rho / 2+\phi_{j} \rho$, which is the lowest productivity level within group $I_{j}$, plus a term $\rho c / 2$, which is half of the distribution of the productivity level within the group.

To solve for the variance, rewrite $(\mathrm{A} 1)$ as

$$
\int_{i \in I_{j}}\left(-\rho / 2+\rho i-\bar{q}_{j}\right)^{2} \frac{1}{c} d i
$$

where $\bar{q}_{j}$ is given by (A2). By evaluating the integral, the variance can be expressed as

$$
\int_{i \in I_{j}}\left(q_{i}-\bar{q}_{j}\right)^{2} \frac{1}{c} d i=\frac{c^{2} \rho^{2}}{12} .
$$

The coordination cost which is assumed to be proportional to the within-group variance is then equal to

$$
H_{j}(c, \rho)=H(c, \rho)=\frac{c^{2} \rho^{2}}{12}
$$




\section{B Choice of contract length and the nominal wage}

\section{B.1 The loss function}

Define the surplus function $\tau\left(l_{i t}\right)$ as the total consumer and producer surplus from having employment equal to $l_{i t}$. Further, use (2) and (3) to solve for the corresponding wage rates

$$
\begin{aligned}
& w_{i t}^{d}\left(l_{i t}^{d}\right)=p_{t}+\theta_{t}+q_{i}+\ln a-\frac{1}{\mu} l_{i t}^{d}, \\
& w_{i t}^{s}\left(l_{i t}^{s}\right)=p_{t}+\frac{1}{\delta} l_{i t}^{s} .
\end{aligned}
$$

The total surplus function then solves

$$
\tau\left(l_{i t}\right)=\int_{0}^{l_{i t}}\left(w_{i t}^{d}(l)-w_{i t}^{s}(l)\right) d l
$$

which gives the following value for $\tau\left(l_{i t}\right)$ :

$$
\tau\left(l_{i t}\right)=\left(\theta_{t}+q_{i}+\ln a\right) l_{i t}-\frac{\delta+\mu}{2 \delta \mu} l_{i t}^{2},
$$

with the first derivative $\tau^{\prime}\left(l_{i t}\right)=0$ at the efficient level of employment $l_{i t}^{*}$ equal to $\delta \mu /(\delta+\mu)\left(\theta_{t}+q_{i}+\ln a\right)$ and with the second derivative, $\tau^{\prime \prime}\left(l_{i t}\right)<0$. Thus, the surplus function takes its maximum value at the efficient level of employment.

The loss from preset nominal wages can then be calculated as the difference between the surplus with $l_{i t}=l_{i t}^{*}$ and the surplus with $l_{i t} \neq l_{i t}^{*}$. The loss function is denoted by $f\left(l_{i t}\right)$ and equal to

$$
f\left(l_{i t}\right)=\int_{l_{i t}}^{l_{i t}^{*}}\left[w_{i t}^{d}(l)-w_{i t}^{s}(l)\right] d l=\left(\theta_{t}+q_{i}+\ln a\right)\left(l_{i t}^{*}-l_{i t}\right)-\frac{\delta+\mu}{2 \delta \mu}\left[\left(l_{i t}^{*}\right)^{2}-l_{i t}^{2}\right] .
$$

A second-order Taylor-approximation of $f\left(l_{i t}\right)$ around the efficient level $l_{i t}^{*}$ then gives the following expression for the change in the surplus from prefixing the wage at a level other than the efficient one:

$$
f\left(l_{i t}\right) \approx f\left(l_{i t}^{*}\right)+f^{\prime}\left(l_{i t}^{*}\right)\left(l_{i t}-l_{i t}^{*}\right)+f^{\prime \prime}\left(l_{i t}^{*}\right)\left(l_{i t}-l_{i t}^{*}\right)^{2} .
$$

By definition of $f\left(l_{i t}\right), f\left(l_{i t}^{*}\right)$ must be zero. Furthermore, $f^{\prime}\left(l_{i t}^{*}\right)=0$, since the function $f\left(l_{i t}\right)$ reaches its minimum at $l_{i t}^{*}$. By evaluating the second derivative, equation (B1) becomes

$$
f\left(l_{i t}\right) \approx-\frac{\delta+\mu}{\delta \mu}\left(l_{i t}-l_{i t}^{*}\right)^{2}
$$




\section{B.2 Proposition 1}

From (20), we find that the derivative of $x$ with respect to $c$ is determined by

$$
\frac{\partial x}{\partial c}=x^{-1 / 2}\left[\frac{c H_{c}-H-F}{k^{2}(1-b)^{2} \sigma_{\theta}^{2} c^{2}}\right] .
$$

From the assumptions about the coordination cost, $c H_{c}-H=(\alpha-1) H$ which is positive, since $\alpha>1$. Furthermore, $\partial\left(c H_{c}-H\right) / \partial c=c H_{c c}$ is positive since $H_{c c}=$ $(\alpha-1) \alpha c^{\alpha-2} \rho^{\beta}$. This means that for a sufficiently large $F, \partial x / \partial c<0$ at lower levels of c. After a cut-off point where $c H_{c}-H=F, \partial x / \partial c>0$.

\section{Choice of the degree of centralization}

\section{C.1 Existence of equilibrium to equation (23)}

Rewrite equation (23) as

$$
\frac{k^{2} \rho^{2} c^{3} x}{6}+c H_{c}-F-H=0
$$

Fix all variables apart from $c$ and denote the left-hand side of $(\mathrm{C} 1)$ by $f(c)$. The function $f(c)$ fulfills $f(0)=-F$ and $\partial f / \partial c=k^{2} \rho^{2} c^{2} x / 2+c H_{c c}$. Since $\partial f / \partial c$ is strictly positive for any $c$ greater than zero, there exists a unique equilibrium to $(\mathrm{C} 1)$ which fulfills $f(c)=0$.

The conditions for a minimum are fulfilled, since $\partial f / \partial c>0$ at an optimum choice of $c$.

\section{Comparative statics}

\section{D.1 Proofs of propositions 3 to 6}

Equation, (20) and (23) can be rewritten as the following implicit equations:

$$
\begin{gathered}
k^{2}(1-b)^{2} \sigma_{\theta}^{2} c x^{2}-2 F-2 H=0 \\
\frac{k^{2} \rho^{2} c^{3} x}{6}+c H_{c}-F-H=0 .
\end{gathered}
$$

Start by looking at the case $d c / d \rho$. Total differentiation of (D1) and (D2), holding $F, \sigma_{\theta}^{2}$ and $\lambda$ constant, gives

$$
2(k-z b)^{2} \sigma_{\theta}^{2} c x d x+k^{2}(1-b)^{2} \sigma_{\theta}^{2} x^{2} d c-2 H_{c} d c-2 H_{\rho} d \rho=0
$$

and

$$
\frac{k^{2} \rho^{2} c^{2} x}{2} d c+\frac{k^{2} \rho c^{3} x}{3} d \rho+\frac{k^{2} \rho^{2} c^{3}}{6} d x+c H_{c c} d c+c H_{c \rho} d \rho-H_{\rho} d \rho=0
$$


By solving for $d x$ from (D3), we get

$$
d x=\frac{2\left(H_{c} d c+H_{\rho} d \rho\right)-k^{2}(1-b)^{2} \sigma_{\theta}^{2} x^{2} d c}{2 k^{2}(1-b)^{2} \sigma_{\theta}^{2} c x} .
$$

By inserting the expression for $d x$ into (D4), we can now evaluate the differentiate of $c$ with respect to $\rho$, equal to:

$$
\frac{d c}{d \rho}=\frac{H_{\rho}-c H_{c \rho}-\frac{k^{2} \rho c^{2}}{3}\left(c x+\frac{H_{\rho} \rho}{2 k^{2}(1-b)^{2} \sigma_{\theta}^{2} x}\right)}{c H_{c c}+\frac{5 k^{2} \rho^{2} c^{2} x}{12}+\frac{H_{c} k^{2} \rho^{2} c^{2}}{6 k^{2}(1-b)^{2} \sigma_{\theta}^{2} x}} .
$$

The denominator is positive so that the sign of this expression is determined by the numerator. Under the assumptions about the coordination cost $H(c, \rho)=c^{\alpha} \rho^{\beta}$ with $\alpha>1$ and $\beta>0$, the term $H_{\rho}-c H_{c \rho}$ is negative and equal to $c^{\alpha} \rho^{\beta-1} \beta(1-\alpha)$. This means that the total derivative is negative.

To find $d c / d \lambda$, we differentiate (D1) and (D2), holding $F, \sigma_{\theta}^{2}$ and $\rho$ constant, which gives

$$
2 k^{2}(1-b)^{2} \sigma_{\theta}^{2} c x d x+k^{2}(1-b)^{2} \sigma_{\theta}^{2} x^{2} d c-2 k(1-b) z \sigma_{\theta}^{2} c x^{2} \frac{\partial b}{\partial \lambda} d \lambda-2 H_{c} d c=0
$$

and

$$
\frac{k^{2} \rho^{2} c^{2} x}{2} d c+\frac{k^{2} \rho^{2} c^{3}}{6} d x+c H_{c c} d c=0 .
$$

By solving for $d x$ from (D6) and inserting this into (D7), we obtain the following expression for $d c / d \lambda$ :

$$
\frac{d c}{d \lambda}=\frac{-\frac{k^{2} \rho^{2} z c^{3} x}{6 k(1-b)} \frac{\partial b}{\partial \lambda}}{c H_{c c}+\frac{5 k^{2} \rho^{2} c^{2} x}{12}+\frac{H_{c} k^{2} \rho^{2} c^{2}}{6 k^{2}(1-b)^{2} \sigma_{\theta}^{2} x}}
$$

where $d b / d \lambda>0$. Thus, $d c / d \lambda<0$.

Similarly, totally differentiating (D1) and (D2) to find $d c / d \sigma_{\theta}^{2}$, holding $F, \rho$ and $\lambda$ constant gives the following expressions

$$
\begin{gathered}
2 k^{2}(1-b)^{2} \sigma_{\theta}^{2} c x d x+k^{2}(1-b)^{2} \sigma_{\theta}^{2} x^{2} d c+k^{2}(1-b)^{2} c x^{2} d \sigma_{\theta}^{2}-2 H_{c} d c=0 \\
\frac{k^{2} \rho^{2} c^{2} x}{2} d c+\frac{k^{2} \rho^{2} c^{3}}{6} d x+c H_{c c} d c=0 .
\end{gathered}
$$

Solving for $d x$ from (D9) and inserting it into (D10) gives the following relation between $c$ and $\sigma_{\theta}^{2}$ :

$$
\frac{d c}{d \sigma_{\theta}^{2}}=\frac{\frac{k^{2} \rho^{2} c^{3} x}{12 \sigma_{\theta}^{2}}}{c H_{c c}+\frac{5 k^{2} \rho^{2} c^{2} x}{12}+\frac{H_{c} k^{2} \rho^{2} c^{2}}{6 k^{2}(1-b)^{2} \sigma_{\theta}^{2} x}}>0 .
$$


Finally, differentiating (D1) and (D2) with respect to $F, x$ and $c$ to find $d c / d F$ gives the following equations:

$$
\begin{gathered}
2 k^{2}(1-b)^{2} \sigma_{\theta}^{2} c x d x+k^{2}(1-b)^{2} \sigma_{\theta}^{2} x^{2} d c-2 d F-2 H_{c} d c=0, \\
\frac{k^{2} \rho^{2} c^{2} x}{2} d c+\frac{k^{2} \rho^{2} c^{3}}{6} d x+c H_{c c} d c-d F=0 .
\end{gathered}
$$

This gives $d c / d F$ equal to

$$
\frac{d c}{d F}=\frac{1-\frac{k^{2} \rho^{2} c^{2}}{6 k^{2}(1-b)^{2} \sigma_{\theta}^{2} x}}{c H_{c c}+\frac{5 k^{2} \rho^{2} c^{2} x}{12}+\frac{H_{c} k^{2} \rho^{2} c^{2}}{6 k^{2}(1-b)^{2} \sigma_{\theta}^{2} x}} \lessgtr 0,
$$

where the sign depends on the relative size of two opposite effects.

\section{E Industrial relations since 1985}

\section{E.1 Austria}

Austria's political system is among the most corporatist of the western countries, based upon close cooperation between state, capital and labor. Unionism is highly centralized and the Austrian Trade Union Federation encompasses the country's entire unionship and consists of 14 affiliates which cover the whole economy. Collective bargaining is highly inclusive (90\% of the employees), conducted at lower bargaining levels, but with strong macro-economic coordination. Bargaining is synchronized, and contract duration is normally between 8 and 12 months. ${ }^{30}$

\section{E.2 Australia}

Up until 1987, industrial relations were characterized by centralized wage fixing. The Industrial Relation Act of 1988 provided scope for agreements outside the national wage principles, and a trend towards decentralization began. Unions are rather weak, with union density around 30\%. Legislation has reduced the power of unions and new changes in the legislation are under way. The average contract duration has increased from 10.4 months in 1992 to 15.8 months in $1994 .^{31}$

\footnotetext{
${ }^{30}$ The material has been collected from Ferner and Hyman (1998), OEGB (1999) and SOU (1998).

${ }^{31}$ Hunt and Provis (1995).
} 


\section{E.3 Belgium}

The Belgian system is characterized by a pattern of intersectorial agreements covering the entire private sector. The agreements provide the framework for employment policy over the subsequent 2-year period and are known as "social planning" agreements. There is a highly institutionalized pyramid of negotiations with the central agreement, initiating intersectorial, sectorial and company-level collective agreements. Wages are automatically linked to inflation. ${ }^{32}$

\section{E.4 Denmark}

Since the 1980s, there has been a trend from national multi-industry bargaining to national single-industry bargaining, with collective bargaining covering $70 \%$ of the work force. Bargaining is highly synchronized and takes place every second year. For the remaining period, agreements are implemented and no bargaining takes place. There is also an element of pattern bargaining, with one of the unions (usually metal workers) setting the pace for the others. ${ }^{33}$

\section{E.5 Finland}

The Finnish system increasingly resembles the Scandinavian model, with a very high coverage of collective agreements (95\%). Its most notable feature is the importance of centralized national agreements between the confederations of employers and unions. There is a strong political element in the system of collective bargaining, with the government facilitating agreements by promising measures such as tax reforms and changes in the labor law. The system is biased towards political compromise and consensus. Contracts are usually signed for $2-3$ years. ${ }^{34}$

\section{E.6 France}

In France, industrial conflict and legal intervention, rather than collective bargaining, has characterized industrial relations. There are strong links between political parties and unions, and trade unions are characterized by fragmentation, rivalry and low union density. The French state has tried to incorporate unions by treating them as partners, and it has used legal intervention to compensate for their organizational weakness. The

\footnotetext{
${ }^{32}$ Ferner and Hyman (1998).

${ }^{33}$ Ferner and Hyman (1998) and SOU (1998).

${ }^{34}$ Ferner and Hyman (1998) and SOU (1998).
} 
collective bargaining system is structured around the three levels of multi-industry, industry and company bargaining where company bargaining has become the key factor in regulating industrial relations. Multi-industry agreements set the framework within which negotiations take place and there is a statuary obligation to negotiate annually. ${ }^{35}$

\section{E.7 Germany}

The most important part of the German model is the dual structure of interest representation. Unions and employers' associations are responsible for collective bargaining, usually at the sectorial and the regional level; work councils and management for relations at the company level. Collective bargaining is relatively centralized and policies are coordinated at the sectorial level; Pilot agreement in key industries (the metal sector) set the standard for the other industries and although sectorial bargaining is usually undertaken at the regional level, it is centrally directed by the national organizations. In the past, the majority of contracts were one-year contracts. German employers try to promote longer contracts, and in 2000, most contracts lasted for two years. ${ }^{36}$

\section{E.8 Ireland}

Collective bargaining is at the center of the Irish system of industrial relations. Most workers have their terms and conditions of employment settled by collective agreements, and it has been long-term public policy to support this system, which is influenced by corporatist tendencies. In the 1970s, national wage agreements covering the whole workforce were negotiated. In the 1980s, there were no centralized agreements, but negotiations were still coordinated with a norm setting the standard for the negotiators. Since 1987, there has been a return to national agreements and the period has been characterized by national agreements with a duration of three years. ${ }^{37}$

\section{E.9 Italy}

In Italy, trade unions are less regulated than elsewhere in Europe and until 1990, strike action was almost unconstrained by law, which resulted in a large number of strikes. The 1946 agreement on indexing wages to the cost of living every three months has been a key element of industrial relations in Italy. This agreement was nullified in 1991 and replaced

\footnotetext{
${ }^{35}$ Ferner and Hyman (1998).

${ }^{36}$ Confederation of German Employers (BDA) (2000), Ferner and Hyman (1998) and SOU (1998).

${ }^{37}$ Ferner and Hyman (1998) and SOU (1998).
} 
with a new system, providing for four-year contracts with a reopening clause after the second year, to adjust wages to actual inflation. ${ }^{38}$

\section{E.10 Japan}

Labor-management relations in Japan have not changed significantly in the last two decades. The labor market is characterized by company-based unions, a seniority based wage profile and long-term employment with work force adjustments through internal training and relocation. In the wage bargaining process, the "spring labor offensive" has played an important role since 1955. Unions and employers negotiate every year, with 1-year contracts as the outcome. In the wage talks, negotiations are primarily conducted between individual companies and their company-based unions. In this sense, wage talks are decentralized. However, the process can be regarded as centralized in the sense that both the union- and the employer side are strongly coordinated, with the same wage level agreed in almost all industries. ${ }^{39}$

\section{E.11 Netherlands}

About $80 \%$ of the working population is covered by collective agreements. Until 1970, collective bargaining was heavily centralized and government-influenced. Thereafter, sectorial and company bargaining became predominant, but the system still has a strong element of coordination. Until 1982, most of the wage increment was determined by a system of price indexation. As inflation rose, this system was abandoned for free negotiations. The usual contract duration varies from 1 to 2 years and is freely determined by the agreement. ${ }^{40}$

\section{E.12 New Zeeland}

Reforms in the labor market have been substantial since the mid-1980s. A new legal framework, the Employment Contracts Act, was introduced in 1991 and a highly decentralized wage-bargaining system has replaced a complex system of industry-wide bargaining. The coverage of collective bargaining has subsequently fallen by half, to around $40 \%$ of the working population, and union density has fallen from around $45 \%$ to $30 \%$ of the work

\footnotetext{
${ }^{38}$ Ferner and Hyman (1998).

${ }^{39}$ Inoue (1999).

${ }^{40}$ Confederation of Netherlands Industry and Employers (VNO) (2000), Ferner and Hyman (1998) and SOU (1998).
} 
force. Between 1993 and 1995, the average duration of contracts was 3.8 quarters. $^{41}$

\section{E.13 Norway}

Union density is lower in Norway than in the other Scandinavian countries, partly because unemployment insurance is provided by the state and not by the unions. Since 1987, there has been a reintroduction of income policies and a re-centralization of collective bargaining, which covers around $70 \%$ of the working population. Collective bargaining does not only cover pay and working conditions, but also broader issues of social policies, such as pension rights and sickness benefits. Negotiations are highly coordinated, and since 1968, there have been bargaining rounds every two years. There is also a renegotiation clause that opens for renegotiations after 12 months. ${ }^{42}$

\section{E.14 Spain}

The Spanish system resembles the French case, with close links between unions and political parties, legally extendable collective agreements, representation in tripartite bodies and other measures that have allowed the union movement to consolidate but, at the same time, have weakened their independence. Around $90 \%$ of the working population are covered by collective agreements and the annual process of collective bargaining is relatively centralized and directed from the central employers' and unions' organizations. Lately, major reforms have taken place which increase the scope of local negotiations between employers and employees. The average term of agreements is 27 months. $^{43}$

\section{E.15 Sweden}

The Swedish model has traditionally been characterized by high union density and a high coverage of collective agreements. There has been a combination of decentralization and centralization of wage bargaining in a self-regulated system, where government intervention has been rare. One recent tendency is the continued advance of decentralization, with an increase in the scope of work place negotiations within the framework of industry agreements. Both the synchronization and the duration of contracts have been highly coordinated in the 1990, with a contract length of 2 - 3 years. ${ }^{44}$

\footnotetext{
${ }^{41}$ Chapple (1996), New Zeeland Council of Trade Unions (2000) and OECD (1998).

${ }^{42}$ Confederation of Norwegian Business and Industry (2000), Ferner and Hyman (1998) and SOU (1998).

${ }^{43}$ Ferner and Hyman (1998) and CEOE (1999).

${ }^{44}$ Ferner and Hyman (1998) and SOU (1998).
} 


\section{E.16 Switzerland}

The Swiss system is characterized by a structure of social partnership dating back to the 1930s. Neither the right to collective organization nor the right to strike is included in the Swiss constitution and unions are relatively weak. Employment relations have been classified as liberal corporativism, with the corporatist arrangements found at the sectorial level. The principal instrument of employment is the sectorial agreement (GAV), which lasts for 3 to 5 years, supplemented by annual negotiations to adjust wages to the cost of living. By law, agreements only cover union members, but non-union employees are usually treated the same way as union members. ${ }^{45}$

\section{E.17 The UK}

The period since 1979 has been characterized by the longest recorded decline in trade union membership and a fall in strike rates to their lowest levels ever. Since the mid1980s, the changes have been accompanied by a strong decline in the role of collective bargaining. There has been a trend from multi-employer to single-employer bargaining and pay systems have been oriented towards company performance. In 1990, half of the private sector's employees were covered by collective agreements and out of these, most were single employer contracts. ${ }^{46}$

\section{E.18 The US}

In the US, unions have traditionally been weak with collective agreements covering only $20 \%$ of the labor force. Up to the 1980s, so-called pattern bargaining at the industry level was common but today, negotiations usually take place at the company level. Contract duration has traditionally been long in the US, earlier averaging 3 years, but lately increasing to $5-6$ years. ${ }^{47}$

\footnotetext{
${ }^{45}$ Ferner and Hyman (1998).

${ }^{46}$ Ferner and Hyman (1998) and SOU (1998).

${ }^{47} \mathrm{SOU}(1998)$.
} 
Table I: The data

\begin{tabular}{lllllllllll}
\hline & $\mathbf{x}_{\mathbf{1}}$ & $\mathbf{x}_{\mathbf{2}}$ & $\mathbf{E M S}_{\mathbf{1}}$ & $\mathbf{E M S}_{\mathbf{2}}$ & $\mathbf{C B I}_{\mathbf{1}}$ & $\mathbf{C B I}_{\mathbf{2}}$ & $\mathbf{H E T}_{\mathbf{1}}$ & $\mathbf{H E T}_{\mathbf{2}}$ & $\mathbf{V A R}_{\mathbf{1}}$ & $\mathbf{V A R}_{\mathbf{2}}$ \\
\hline Australia & 0 & 1 & 2 & 1 & 0.38 & 0.46 & 0.79 & 1.22 & 0.69 & 2.83 \\
Austria & 0 & 0 & 2 & 2 & 0.60 & 0.57 & 2.89 & 9.81 & 1.20 & 1.05 \\
Belgium & 0 & 1 & 2 & 2 & 0.30 & 0.36 & 6.18 & 8.26 & - & 0.69 \\
Canada & 1 & 1 & 1 & 1 & 0.41 & 0.46 & 1.67 & 6.38 & 0.52 & 0.90 \\
Denmark & 0 & 1 & 3 & 2 & 0.38 & 0.44 & 1.05 & 1.28 & - & 0.93 \\
Finland & 1 & 1 & 3 & 2 & 0.31 & 0.32 & 1.17 & 1.43 & 1.58 & 1.44 \\
France & 1 & 0 & 2 & 2 & 0.27 & 0.37 & 1.76 & 2.94 & 0.74 & 2.88 \\
Germany & 0 & 1 & 2 & 2 & 0.79 & 0.80 & 1.80 & 3.83 & 0.89 & 0.91 \\
Italy & 2 & 2 & 1 & 3 & 0.07 & 0.13 & 1.27 & 3.85 & 1.05 & 1.00 \\
Japan & 0 & 0 & 1 & 1 & 0.46 & 0.56 & 2.74 & 11.51 & 1.05 & 0.94 \\
Netherlands & 0 & 1 & 2 & 2 & 0.49 & 0.49 & 2.19 & 2.07 & 0.50 & 0.98 \\
Norway & 1 & 1 & 3 & 3 & 0.25 & 0.25 & 1.49 & 6.64 & 1.05 & 1.32 \\
Spain & 1 & 1 & 2 & 2 & 0.26 & 0.36 & 2.30 & 7.11 & 0.81 & 0.67 \\
Sweden & 1 & 1 & 3 & 2 & 0.26 & 0.25 & 0.78 & 5.86 & 1.25 & 1.34 \\
Switzerland & 2 & 2 & - & - & 0.87 & 0.74 & - & - & 1.87 & 1.64 \\
UK & 0 & 0 & 2 & 1 & 0.25 & 0.25 & 3.19 & 6.82 & 0.93 & 1.03 \\
US & 2 & 2 & 1 & 1 & 0.63 & 0.55 & 1.83 & 9.78 & 0.88 & 1.06 \\
\hline Mean & 0.71 & 0.94 & 2 & 1.81 & 0.41 & 0.43 & 2.07 & 5.55 & 1.00 & 1.27 \\
Min. & 0 & 0 & 1 & 1 & 0.07 & 0.13 & 0.78 & 1.22 & 0.50 & 0.67 \\
Max. & 2 & 2 & 3 & 3 & 0.87 & 0.74 & 6.18 & 11.51 & 1.87 & 2.88
\end{tabular}

Table I: The data

\begin{tabular}{lllll}
\hline & ESUM $_{\mathbf{1}}$ & ESUM $_{\mathbf{2}}$ & OECD $_{\mathbf{1}}$ & OECD $_{\mathbf{2}}$ \\
\hline Australia & 2 & 1 & 2.25 & 1.5 \\
Austria & 3 & 3 & 2.25 & 2.25 \\
Belgium & 2 & 2 & 2.25 & 2.25 \\
Canada & 1 & 1 & 1 & 1 \\
Denmark & 3 & 3 & 2.25 & 2 \\
Finland & 3 & 2 & 2.5 & 2.25 \\
France & 2 & 2 & 2 & 2 \\
Germany & 3 & 3 & 2 & 2 \\
Italy & 1 & 3 & 1.75 & 2 \\
Japan & 1 & 1 & 1 & 1 \\
Netherlands & 2 & 3 & 2 & 2 \\
Norway & 3 & 3 & 2 & 2.5 \\
Spain & 3 & 2 & 2.25 & 2 \\
Sweden & 3 & 2 & 3 & 2 \\
Switzerland & - & - & 2 & 2 \\
UK & 2 & 1 & 2 & 1.5 \\
US & 1 & 1 & 1 & 1 \\
\hline Mean & 2.2 & 2.1 & 2 & 1.8 \\
Min. & 1 & 1 & 1 & 1 \\
Max. & 3 & 3 & 3 & 2.5
\end{tabular}


Table II: OLS results for contract length

\begin{tabular}{ccc}
\hline $\begin{array}{c}\text { Dependent } \\
\text { Variable }\end{array}$ & $\begin{array}{c}\text { Contract } \\
\text { length, } \mathrm{x}\end{array}$ & $\begin{array}{c}\text { Theoretical } \\
\text { Predictions }\end{array}$ \\
\hline EMS & -2.47 & - \\
& $(0.90)$ & + \\
EMS $^{2}$ & 0.61 & \\
& $(0.23)$ & - \\
CBI & 1.79 & - \\
& $(0.92)$ & No \\
VAR & 1.02 & No \\
& $(0.54)$ & Predictions \\
GER & -1.00 & \\
& $(0.34)$ & \\
FRE & 0.68 & \\
& $(0.29)$ & Predictions \\
CONST & 1.31 & \\
& $(0.98)$ & \\
\hline Adjusted ${ }^{2}$ & 0.36 & \\
No. Obs. & 30 & \\
\hline
\end{tabular}

Standard errors are reported in the parenthesis

Table III: OLS results for the degree of centralization

\begin{tabular}{ccc}
\hline $\begin{array}{c}\text { Dependent } \\
\text { Variable }\end{array}$ & $\begin{array}{c}\text { Centralization } \\
\text { EMS }\end{array}$ & $\begin{array}{c}\text { Theoretical } \\
\text { Predictions }\end{array}$ \\
\hline POP & -0.003 & \\
& $(0.002)$ & No \\
GER & 0.44 & Predictions \\
& $(0.26)$ & No \\
SCA & 1.20 & Predictions \\
& $(0.26)$ & No \\
FRE & 0.68 & Predictions \\
& $(0.23)$ & No \\
TIME & -0.23 & Predictions \\
& $(0.17)$ & No \\
CONST & 1.55 & Predictions \\
& $(0.23)$ & \\
\hline Adjusted R & 0.53 & \\
No. Obs. & 32 & \\
\hline
\end{tabular}

Standard errors are reported in the parenthesis 
Table IV: Ordered probit results for contract length

\begin{tabular}{cc}
\hline $\begin{array}{c}\text { Dependent } \\
\text { variable }\end{array}$ & $\begin{array}{c}\text { Contract length } \\
\mathrm{x}\end{array}$ \\
\hline c1 & 1.76 \\
& $(0.70)$ \\
$\mathrm{c} 3$ & 1.59 \\
& $(0.89)$ \\
CBI & 4.84 \\
& $(2.43)$ \\
VAR & 2.66 \\
& $(1.43)$ \\
FRE & 1.80 \\
& $(0.79)$ \\
GER & -2.71 \\
& $(0.97)$ \\
\hline Pseudo R & 0.35 \\
No. Obs. & 30 \\
Log likelihood & -19.0 \\
\hline Standard errors are reported in the parenthesis
\end{tabular}

Table V: Predicted probabilities for various contract lengths depending on the degree of centralization

\begin{tabular}{cccc} 
& $\begin{array}{c}\text { Short-term } \\
\text { contracts }\end{array}$ & $\begin{array}{c}\text { Intermediate-term } \\
\text { contracts }\end{array}$ & $\begin{array}{c}\text { Long-term } \\
\text { contracts }\end{array}$ \\
\hline $\begin{array}{c}\text { Low degree of } \\
\text { centralization }\end{array}$ & 0.22 & 0.58 & 0.21 \\
$\begin{array}{c}\text { Intermediate degree of } \\
\text { centralization } \\
\begin{array}{c}\text { High degree of } \\
\text { centralization }\end{array}\end{array}$ & 0.49 & 0.47 & 0.04 \\
\hline
\end{tabular}

Low degree of centralization is when $\mathrm{EMS}=1$, intermediate when $\mathrm{EMS}=2$ and high when $\mathrm{EMS}=3$

Table VI: Predicted probabilities for various contract lengths depending on the degree of central bank independence

\begin{tabular}{|c|c|c|c|}
\hline & $\begin{array}{l}\text { Short-term } \\
\text { contracts }\end{array}$ & $\begin{array}{l}\text { Intermediate-term } \\
\text { contracts }\end{array}$ & $\begin{array}{c}\text { Long-term } \\
\text { contracts }\end{array}$ \\
\hline $\begin{array}{l}\text { Low degree of central } \\
\text { bank independence }\end{array}$ & 0.27 & 0.62 & 0.11 \\
\hline $\begin{array}{l}\text { High degree of central } \\
\text { bank independence }\end{array}$ & 0.44 & 0.41 & 0.16 \\
\hline
\end{tabular}


Table VII: Ordered probit results for the degree of centralization

\begin{tabular}{cc}
\hline $\begin{array}{c}\text { Dependent } \\
\text { variable }\end{array}$ & $\begin{array}{c}\text { Centralization } \\
\text { EMS }\end{array}$ \\
POP & -0.02 \\
& $(0.01)$ \\
FRE & 2.08 \\
& $(0.76)$ \\
SCA & 3.32 \\
& $(0.94)$ \\
GER & 1.53 \\
& $(0.85)$ \\
TIME & -0.55 \\
& $(0.48)$ \\
\hline Pseudo R & 0.45 \\
No. Obs. & 32 \\
Log likelihood & -17.79 \\
Standard errors are reported in the parenthesis &
\end{tabular}

Standard errors are reported in the parenthesis 


\section{SEMINAR PAPER SERIES}

The Series was initiated in 1971. For a complete list of Seminar Papers, please contact the Institute.

$\underline{2000}$

683. Harry Flam and Per Jansson:

684. Harry Flam and M. June Flanders:

685. Assar Lindbeck:

686. Mats Persson:

687. Lars E.O. Svensson:

688. Lars E.O. Svensson and Michael Woodford:

$\underline{2001}$

689. Lars E.O. Svensson and Michael Woodford:

690. Lars Calmfors

691. Assar Lindbeck and Sten Nyberg

692. Lars Calmfors and Asa Johansson

693. Peter Svedberg

694. Assar Lindbeck

695. Antoni Calvó-Armengol and Yves Zenou

696. Mats Persson and Claes-Henrik Siven

697. Magnus Henrekson and Mats Persson
EMU Effects on International Trade and Investment. 42 pp.

The Young Ohlin on the Theory of "Interregional and International Trade". $18 \mathrm{pp}$.

Pensions and Contemporary Socioeconomic Change. 27 pp.

Five Fallacies in the Social Security Debate. 16 pp.

The Zero Bound in an Open Economy: A Foolproof Way of Escaping from a Liquidity Trap. 44 pp.

Indicator Variables for Optimal Policy. 43 pp.

Indicator Variables for Optimal Policy under Assymetric Information.

Wages and Wage-Bargaining Institutions in the EMU - A Survey of the Issues.

Raising Children to Work Hard: Altruism, Work Norms and Social Insurance.

Unemployment Benefits, Contract Length and Nominal Wage Flexibility.

Undernutrition Overestimated.

Changing Tides for the Welfare State.

Job Matching, Social Network and Word-of-Mouth Communication.

Incentive and Incarceration Effects in a General Equilibrium Model of Crime.

The Effects on Sick Leave of Changes in the Sickness Insurance System. 
699. Peter Svedberg

700. Lars Calmfors, Anders Forslund, and Maria Hemström.

701. Kjetil Storesletten

702. Kjetil Storesletten, Chris Telmer, and Amir Yaron

703. Kjetil Storesletten, Chris Telmer, and Amir Yaron

704. John Hassler, José V. Rodriguez Mora, Kjetil Storesletten, and Fabrizio Zilibotti

705. John Hassler, José V. Rodriguez Mora, Kjetil Storesletten, and Fabrizio Zilibotti

706. David Strömberg

707. Paolo Epifani and Gino A. Gancia

708. Åsa Johansson

709. Asa Johansson and Charlotta Groth
Hunger in India - Facts and Challenges.

Does Active Labour Market Policy Work? Lessons from the Swedish Experiences.

Fiscal Implications of Immigration.

Consumption and Risk Sharing over the Life Cycle.

Asset Pricing with Idiosynchratic Risk and Overlapping Generations.

The Survival of the Welfare State.

A Positive Theory of Geographical Mobility and Social Insurance.

Optimal Campaigning in Presidential Elections: The Probability of Being Florida.

The Skill Bias of World Trade.

The Interaction Between Labor Market Policy and Monetary Policy: An Analysis of Time Inconsistency Problems.

Bargaining Structure and Nominal Wage Flexibility

ISSN 0347-8769

Stockholm, 2002

Institute for International Economic Studies 